\title{
Causative agents and their antimicrobial sensitivities in hospitalised children with recurrent urinary tract infections: Experience in a paediatric nephrology unit
}

\author{
*Niranjalee Samanthika Egodawaththe ${ }^{1}$, Shenal Thalgahagoda ${ }^{1}$, Gihani Vidanapathirana ${ }^{1}$ \\ Sri Lanka Journal of Child Health, 2022; 51(1): 75-83 \\ DOI: http://dx.doi.org/10.4038/sljch.v51i1.10000
}

\begin{abstract}
Introduction: Urinary tract infection (UTI) has a significant morbidity highlighting the importance of preventing recurrences. Knowledge on aetiological agents and their antibiotic sensitivities is crucial for proper management of affected children.
\end{abstract}

Objectives: To determine the causative microorganisms and their antibiotic sensitivity pattern in patients with recurrent UTIs on uroprophylaxis and to compare the first episode of UTI with recurrent UTIs regarding causative organisms and antibiotic sensitivity.

Method: A descriptive study was done at Teaching Hospital Peradeniya, recruiting children aged 1 month to 14 years, admitted from $1^{\text {st }}$ May 2019 to $30^{\text {th }}$ April 2020 with breakthrough febrile or symptomatic UTIs after being on antibiotic prophylaxis. Details were collected using a validated and pre-tested questionnaire.

Results: A total of 141 UTIs of 52 children were analysed. There were $31(59.6 \%)$ boys; $76.3 \%$ episodes were febrile and $22.7 \%$ were afebrile but symptomatic UTIs. Micturating cystourethrogram revealed that $29(56 \%)$ children had vesico-ureteric reflux; renal scarring was noted in the majority; 24 (46.1\%) children had bladder and bowel dysfunction. Constipation was found in 29 (55.7\%). Main pathogens implicated in recurrent UTIs were Escherichia coli (E coli) (55\%), Klebsiella species (14.6\%) and Pseudomonas aeruginosa (13.5\%). First episodes were caused by $E$ coli $(57.7 \%)$, Klebsiella species $(17.3 \%)$ and Proteus mirabilis (11.5\%). Imipenem (89.8\%), amikacin $(87.7 \%)$ and ciprofloxacin $(87.7 \%)$ were the most sensitive

\footnotetext{
${ }^{1}$ Teaching Hospital Peradeniya, Sri Lanka

*Correspondence: samanthika41@gmail.com

iD https//orcid.org/ 0000-0002-8137-0737

(Received on 08 March 2021: Accepted after revision on 23 April 2021)

The authors declare that there are no conflicts of interest

Personal funding was used for the project.

Open Access Article published under the Creative

Commons Attribution CC-BY (c) (i) License
}

antibiotics for $E$ coli. Sensitivity of $E$ coli to cotrimoxazole was significantly decreased during recurrent episodes $(p=0.025)$. More than 2 UTIs were significantly associated with age above 24 months, female gender, constipation, bladder bowel dysfunction (BBD) and renal scarring

Conclusions: Primary and recurrent UTIs in children were mainly caused by $E$ coli. Antibiotic sensitivity rates of $E$. coli were comparatively lower in recurrent UTIs. Age above 24 months, female gender, constipation, BBD and renal scarring showed a significant association with multiple UTI recurrences.

(Key words: Recurrent urinary tract infections, Causative microorganisms, Antibiotic sensitivity patterns, Uroprophylaxis, Children)

\section{Introduction}

Urinary tract infection (UTI) may manifest as the sentinel event of underlying renal anomaly ${ }^{1}$. UTI affects $2 \%$ boys and $8 \%$ girls by the age of 7 years with a prevalence rate of $7 \%$ among febrile infants ${ }^{2,3}$. While haematogenous spread often causes UTI in infancy, it is usually secondary to ascending infection in older children ${ }^{4}$. Escherichia coli ( $E$ coli) is the causative organism in over $80 \%$ of childhood UTI. Klebsiella, Proteus, Enterobacter, Pseudomonas and Serratia species are causative organisms in recurrent UTIs ${ }^{4,5}$. A third to one half of children with UTI have at least one recurrence ${ }^{6}$. Age, gender, race, circumcision status, voiding dysfunction and presence of renal tract structural anomalies can increase the risk of recurrences of UTIs $^{7}$. Bladder bowel dysfunction (BBD) is associated with persistence of vesico-ureteric reflux (VUR) and renal scarring ${ }^{7}$. Long-term consequences of renal scarring include hypertension, preeclampsia and chronic renal insufficiency ${ }^{6}$. As each successive UTI increases the risk of renal damage, avoidance of breakthrough infections is an important goal.

Prophylactic antibiotics are commonly prescribed for children at risk of recurrence. However, there is proven evidence on the occurrence of resistant organisms with continuous uroprophylaxis ${ }^{9}$. Several studies showed that the incidence of UTI in children with low grade VUR is not reduced by antibiotic prophylaxis $^{8,9}$ whereas the PRIVENT trial showed 
that continuous usage of prophylactic antibiotics had substantial benefit in preventing symptomatic UTIs $^{3}$. To the best of our knowledge, there are no published data analysing antimicrobial susceptibility patterns while on prophylactic antibiotics for recurrent UTI in Sri Lanka. Furthermore, a detailed literature review revealed that the urinary pathogens responsible for breakthrough / recurrent UTIs have not been analysed in the local setting.

\section{Objectives}

1. To determine the causative microorganisms and their antibiotic sensitivity pattern in patients with recurrent UTIs on uroprophylaxis.

2. To compare the first episode of UTI with recurrent UTIs with regard to causative organisms and antibiotic sensitivity

\section{Method}

A descriptive cross-sectional study was carried out in the Paediatric Nephrology Unit at Teaching Hospital, Peradeniya, Sri Lanka, a tertiary care facility. Data were collected from $1^{\text {st }}$ May 2019 to $30^{\text {th }}$ April 2020. All the registered children with UTIs aged 1 month to 14 years at the Paediatric Nephrology clinic were observed over the study period and those who were admitted with breakthrough febrile or symptomatic UTIs after being on antibiotic prophylaxis for a minimum onemonth period were recruited. Children not compliant with antibiotic prophylaxis, those already on antibiotics prior to admission, those whose samples grew more than 1 type of micro-organism or fungal infection, those who had other comorbid diseases and those who had not consented for recruitment in the study were excluded.

Fever was defined as a documented temperature of $38^{\circ} \mathrm{C}$, either at home or in the hospital, within one day before or after the urine sample was collected for analysis. Features of symptomatic UTIs included suprapubic, abdominal or flank pain and lower urinary tract symptoms like urgency, frequency and dysuria. Failure to thrive was also considered in infants. Data were collected by a middle grade medical officer (senior house officer or postgraduate trainee) using a questionnaire, which was pre-tested in ten children admitted with breakthrough UTIs and necessary revisions and modifications were done. Details on sociodemographic profile, underlying renal anomalies, type and dosage of uroprophylaxis and microbial sensitivity pattern of the given urine cultures were recorded. Treatment history of first episode, current episode and up to 5 breakthrough UTIs were analysed and entered.
BBD was assessed at study entry by using a modified version of the Dysfunctional Voiding and Incontinence Symptoms Score Questionnaire, initially described by Farhat W, et $\mathrm{al}^{10}$. A score of over 6 for female subjects and over 9 for male subjects was considered to be consistent with BBD. Constipation was defined according to the Rome IV criteria. At least 2 symptoms for a minimum of 1 month were considered to be diagnostic of constipation ${ }^{11}$. UTI was diagnosed by urine culture. We adhered to the National Institute for Health and Care Excellence (NICE) guidelines established in $2017^{12}$. Clean catch mid-stream urine was obtained whenever possible and in case of failure, urethral catheterization or suprapubic aspiration was done. Urine was cultured within 30 minutes of voiding or else the sample was refrigerated at $4^{\circ} \mathrm{C}$ for not more than 24 hours. Semi-quantitative culture was used for urine analysis. Antibiotic sensitivity pattern of the isolates was performed by disc diffusion technique. Documented temperature of $\geq 38.5^{\circ} \mathrm{C}$ with a positive urine culture, was considered as a febrile UTI. Renal scars were recorded according to the dimercaptosuccinic acid (DMSA) findings and graded by a consultant radiologist as per standard classification (Type 1: no more than two scars, Type 2: more than two scars with some normal parenchyma between them, Type 3: generalized damage to whole kidney and Type 4: shrunken kidney with $<10 \%$ of overall function $)^{13}$.

Ethical issues: Study was approved by the Ethics Review Committee of Sri Lanka College of Paediatricians (No. SLCP/ERC/2019/07). Written informed consent was obtained from the parents of the participants.

Statistical analysis: Chi squared test was used to find out the factors which were significantly associated with frequency of UTIs, whereas MannWhitney U test was used to interpret comparisons. Age was dichotomized as below 24 months versus above 24 months, based on guidelines established for imaging and prophylaxis in young children with UTIs $^{14}$. Data was analysed using Statistical Package for Social Sciences 22.0 (SPSS- 22.0).

\section{Results}

During the study period we reviewed the details of recurrent UTIs for 104 children who fulfilled the inclusion criteria. However, 31 children were excluded as their previous clinical records revealed incomplete data. Another 8 had underlying comorbid diseases (neurogenic bladder, chronic kidney disease and immunosuppressive disorders), 9 withdrew consent to participate and 4 did not complete treatment. Ultimately 52 children comprised the study group. A total of 141 episodes of confirmed UTIs of the study population was analysed, of which 52 episodes were initial UTIs and 
89 episodes were recurrent UTIs. Mean age at time of recruitment to the study was $4.5 \pm 3.1$ years (age range 2 months to 13.5 years) whereas mean age at their initial UTI was $2.5 \pm 0.7$ years (age range 1 month to 8.5 years). Baseline demographic and clinical characteristics of the study cohort are described in Table 1.

Table 1: Demographic and clinical characteristics of study population at time of enrollment (n=52)

\begin{tabular}{|c|c|}
\hline Characteristic & Number (\%) \\
\hline $\begin{aligned} & \text { Gender } \\
& \text { Male } \\
& \bullet \text { Circumcised } \\
& \bullet \text { Uncircumcised } \\
& \text { Female } \\
&\end{aligned}$ & $\begin{array}{l}31(59.6) \\
06(11.5) \\
25(48.0) \\
21(40.4)\end{array}$ \\
\hline $\begin{array}{l}\text { Total number of urinary tract infections } \\
2 \\
3 \text { or more }\end{array}$ & $\begin{array}{l}28(53.8) \\
24(46.1) \\
\end{array}$ \\
\hline $\begin{array}{l}\text { Symptom analysis } \\
\text { Only fever } \\
\text { Febrile and symptomatic } \\
\text { Afebrile but symptomatic }\end{array}$ & $\begin{array}{l}12(08.5) \\
97(68.8) \\
32(22.7)\end{array}$ \\
\hline $\begin{array}{l}\text { Micturating cystourethrogram abnormalities }(n=46) \\
\text { Normal } \\
\text { Posterior urethral valves } \\
\text { Unilateral grade } 1-11 \text { reflux } \\
\text { Bilateral grade } 1-11 \text { reflux } \\
\text { Unilateral grade } 111-V \text { reflux } \\
\text { Bilateral grade } 111-\mathrm{V} \text { reflux } \\
\text { Duplex renal system } \\
\text { Isolated bladder diverticula } \\
\text { Other }\end{array}$ & $\begin{array}{l}07(15.2) \\
10(02.2) \\
04(08.7) \\
02(04.3) \\
03(06.5) \\
12(26.0) \\
03(06.5) \\
02(04.3) \\
03(06.5)\end{array}$ \\
\hline $\begin{array}{l}\text { Bladder bowel dysfunction }(n=24) \\
\text { Male } \\
\text { Female }\end{array}$ & $\begin{array}{l}13(54.0) \\
11(45.8) \\
\end{array}$ \\
\hline $\begin{array}{l}\text { Common symptoms }(n=24) \\
\text { Day time incontinence } \\
\text { Urgency } \\
\text { Nocturnal enuresis } \\
\text { Frequency } \\
\text { Withholding manoeuvres (i.e. leg crossing) }\end{array}$ & $\begin{array}{l}18(75.0) \\
15(62.5) \\
13(54.0) \\
09(37.5) \\
06(35.0)\end{array}$ \\
\hline $\begin{array}{l}\text { Constipation }(n=29) \\
\text { Male } \\
\text { Female } \\
\leq 2 \text { bowel movements/week } \\
\text { Painful defaecation } \\
\text { Faecal incontinence } \\
\end{array}$ & $\begin{array}{l}13(44.8) \\
16(55.0) \\
12(41.4) \\
19(65.5) \\
09(31.0)\end{array}$ \\
\hline $\begin{array}{l}\text { DMSA findings }(n=29) \\
\text { Normal } \\
\text { Type } 1 \text { scarring } \\
\text { Type } 2 \text { scarring } \\
\text { Type } 3 \text { scarring } \\
\text { Type } 4 \text { scarring } \\
\text { Other }\end{array}$ & $\begin{array}{l}03(10.3) \\
03(10.3) \\
06(20.7) \\
11(38.0) \\
05(17.2) \\
01(03.5)\end{array}$ \\
\hline $\begin{array}{l}\text { Education level of primary caregiver } \\
\text { Up to Year } 5 \\
\text { Years } 6-11 \\
\text { Advanced level } \\
\text { Tertiary (Degree/ diploma) }\end{array}$ & $\begin{array}{l}06(11.5) \\
20(38.5) \\
18(34.6) \\
08(11.5)\end{array}$ \\
\hline
\end{tabular}

Symptom analysis revealed that $109(77.3 \%)$ episodes were febrile and $32(22.7 \%)$ were afebrile but symptomatic. Forty six $(88.4 \%)$ were evaluated with a micturating cystourethrogram (MCUG) and abnormalities were detected in 39 patients. There were $29(56 \%)$ children with vesico-ureteral reflux (VUR) of any grade. According to the bladderbowel dysfunction questionnaire, 24 (46.1\%) 
children had BBD and their mean age was 5.5 \pm 2.7 years. Female: male ratio of children with BBD was 1.18:1. Most frequently reported urinary symptoms were daytime incontinence, urgency, nocturnal enuresis and frequency. In addition, constipation was found in $29(55.7 \%)$ children. DMSA scans had been performed in 29 children by the time they were enrolled in the study. Twenty five $(86 \%)$ of these children had evidence of renal scarring. Types 1111 renal scarring were seen in $20(68 \%)$ patients and $5(17.2 \%)$ patients had unilateral shrunken kidneys. Analysis of the educational qualifications of the primary caregivers revealed that $38 \%$ completed up to ordinary level while $36 \%$ and $15 \%$ had advanced level and tertiary education, respectively (Table 1).

\section{Distribution of bacterial isolates}

The distribution of uropathogens responsible for recurrent UTIs at different ages in the study sample is detailed in Table 2 . The main bacterial pathogens implicated in recurrent UTIs were successively $E$. coli $(55 \%, \mathrm{n}=49)$, Klebsiella species $(14.6 \% \mathrm{n}=13)$, Pseudomonas aeruginosa (13.5\% $\mathrm{n}=12)$, Enterococcus species $(6.7 \% \mathrm{n}=6)$ and Proteus mirabilis $(6.7 \% \mathrm{n}=6)$. There were $3(3.4 \%)$ episodes caused by unclassified coliforms. Extendedspectrum beta-lactamase (ESBL) producing Enterobactericeae accounted for 17 (19\%) of the total isolates of which ESBL producing E. coli and Klebsiella species were $11(64.7 \%)$ and Klebsiella 6 $(35.3 \%)$ respectively. No staphylococci species or other gram positive organisms were identified.

Table 2: Distribution of uropathogens of recurrent urinary tract infections

\begin{tabular}{|l|c|c|c|}
\hline \multicolumn{1}{|c|}{ Organisms } & $\begin{array}{c}\leq \mathbf{2} \text { years }(\boldsymbol{n}=\mathbf{3 4}) \\
\text { Number }(\mathbf{\%})\end{array}$ & $\begin{array}{c}\text { 2-6 years }(\boldsymbol{n}=\mathbf{3 6}) \\
\text { Number }(\mathbf{\%})\end{array}$ & $\begin{array}{c}\text { 6-14 years }(\boldsymbol{n}=\mathbf{1 9}) \\
\text { Number }(\%)\end{array}$ \\
\hline Escherichia coli $($ ESBL-) & $16(47.0)$ & $14(38.9)$ & $08(42.1)$ \\
Escherichia coli (ESBL+) & $04(11.7)$ & $04(11.1)$ & $03(15.8)$ \\
\hline Klebsiella species (ESBL-) & $01(02.9)$ & $05(13.9)$ & $01(05.3)$ \\
Klebsiella species (ESBL+) & $02(05.9)$ & $02(05.6)$ & $02(10.5)$ \\
\hline Enterococcus species & $02(05.9)$ & $03(08.3)$ & $01(05.3)$ \\
\hline Proteus mirabilis & $04(11.7)$ & $01(2.8)$ & $01(5.3)$ \\
\hline Pseudomonas aeruginosa & $04(11.7)$ & $05(13.9)$ & $03(15.8)$ \\
\hline Unclassified Coliforms & $01(02.9)$ & $02(05.6)$ & $0)$ \\
\hline
\end{tabular}

Commonly prescribed prophylactic antibiotics for recurrent UTIs were cotrimoxazole (35\%), cephalexin $(27.5 \%)$, nitrofurantoin $(23.7 \%)$ and nalidixic acid $(11.2 \%)$. Predominant organisms detected in first episode of UTI were $E$. coli $(57.7 \%$, $\mathrm{n}=30)$, Klebsiella species $(17.3 \%, \mathrm{n}=9)$, Proteus mirabilis (11.5\%, n=6), Pseudomonas aeruginosa
$(7.7 \%, \mathrm{n}=4)$ and Staphylococcus species $(5.7 \%$, $\mathrm{n}=3$ ). Of the total bacterial isolates responsible for primary UTI, 9.6\% $(n=5)$ was caused by ESBL producing $E$. coli. A comparison of the uropathogens of first and recurrent episodes of UTIs is illustrated in Figure 1.

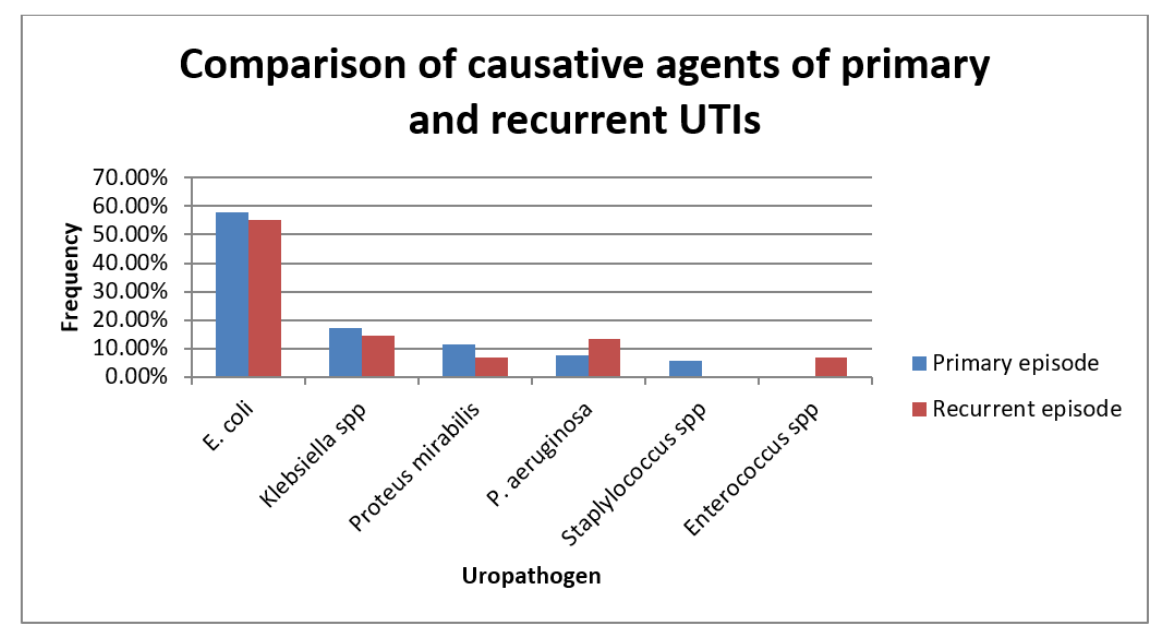

Figure 1: Comparison of causative agents of primary and recurrent UTIS

\section{Antibiotic sensitivity patterns of isolated uropathogens}

The most effective agents against detected uropathogens of recurrent UTIs were imipenem, amikacin and ciprofloxacin as shown in Table 3. In this study, the lowest sensitivity of E. coli was to ampicillin, followed by nalidixic acid, cotrimoxazole and nitrofurantoin. 
Table 3: Antibiotic sensitivity rates of 89 uropathogens isolated in children with recurrent UTIS

\begin{tabular}{|l|c|c|c|c|c|}
\hline \multicolumn{1}{|c|}{ Antibiotic } & $\begin{array}{c}\text { E. coli }(\mathbf{n}=\mathbf{4 9}) \\
(\mathbf{\%})\end{array}$ & $\begin{array}{c}\text { Klebsiella spp } \\
\mathbf{n = 1 3}, \mathbf{( \% )}\end{array}$ & $\begin{array}{c}\text { Enterococcus spp } \\
\mathbf{n = 6 , ( \% )}\end{array}$ & $\begin{array}{c}\text { Proteus mirabilis } \\
\mathbf{n = 6 , ( \% )}\end{array}$ & $\begin{array}{c}\text { P. aeruginosa } \\
\mathbf{n = 1 2}, \mathbf{( \% )}\end{array}$ \\
\hline Ampicillin & 34.7 & 0.7 & 50 & 33.3 & NT \\
\hline Co-amoxiclav & 55.1 & 61.5 & NT & 66.7 & 100 \\
\hline Amikacin & 87.7 & 100.0 & 83.3 & 100 & 75 \\
\hline Gentamycin & 81.6 & 77.0 & NT & 100 & NT \\
\hline Cephalexin & 38.8 & 23.0 & NT & NT & NT \\
\hline Cefuroxime & 69.4 & 69.2 & NT & NT & 100.0 \\
\hline Cefotaxime & 79.6 & 84.6 & NT & NT & 100.0 \\
\hline Ceftazidime & NT & 77.0 & NT & 83.3 & 100.0 \\
\hline Ciprofloxacin & 87.7 & 100.0 & 66.7 & 100.0 & 58.3 \\
\hline Imipenem & 89.8 & 100.0 & 100.0 & 50 & 66.7 \\
\hline Cotrimoxazole & 42.8 & 69.2 & 50 & 16.7 & NT \\
\hline Nitrofurantoin & 44.9 & 61.5 & 83.3 & NT & NT \\
\hline Nalidixic acid & 36.7 & 46.1 & NT & NT & \\
\hline Vancomycin & NT & NT & 100 & & \\
\hline
\end{tabular}

NT- Not Tested

Since $E$ coli was the most frequently identified microorganism causing UTIs, we compared its antimicrobial sensitivity pattern between the first episode and recurrences. As shown in Table 4, antibiotic sensitivity to cotrimoxazole significantly decreased during the recurrent episodes $(p=0.025$, $\mathrm{p}<0.05)$ ).

Table 4: Comparison of antibiotic sensitivity rates of $E$. coli between primary and recurrent UTIs

\begin{tabular}{|l|c|c|c|}
\hline \multicolumn{1}{|c|}{ Antibiotic } & $\begin{array}{c}\text { First episode of UTI (n=27) } \\
\text { Number (\%) }\end{array}$ & $\begin{array}{c}\text { Recurrent episodes of UTIs (n=38) } \\
\text { Number (\%) }\end{array}$ & $\boldsymbol{p}$ value \\
\hline Ampicillin & $11(40.7)$ & $17(34.7)$ & 0.594 \\
\hline Amoxicillin-Clavulanic acid & $18(66.7)$ & $27(55.1)$ & 0.359 \\
\hline Amikacin & $26(96.3)$ & $43(87.7)$ & 0.198 \\
\hline Gentamycin & $24(88.9)$ & $40(81.6)$ & 0.424 \\
\hline Cefuroxime & $20(74)$ & $34(69.4)$ & 0.624 \\
\hline Cefotaxime & $22(81.5)$ & $39(79.6)$ & 0.803 \\
\hline Ciprofloxacin & $26(96.3)$ & $43(87.7)$ & 0.313 \\
\hline Imipenem & $27(100)$ & $44(89.8)$ & 0.138 \\
\hline Co-trimoxazole & $19(70.4)$ & $21(42.8)$ & 0.025 \\
\hline Nitrofurantoin & $20(55.5)$ & $22(44.9)$ & 0.394 \\
\hline
\end{tabular}

Factors associated with recurrent UTIS

Factors associated with recurrence of UTI are described in Table 5. Out of the study variables, more than 2 UTIs were significantly associated with age above 24 months, female gender, constipation, $\mathrm{BBD}$ and renal scarring.

Table 5: Factors associated with recurrent urinary tract infections (UTIS)

\begin{tabular}{|c|c|c|c|}
\hline \multirow[t]{2}{*}{ Associated Factor } & \multicolumn{2}{|c|}{ Frequency of UTIs (\%) } & \multirow[t]{2}{*}{ Significance } \\
\hline & 2 or $<$ episodes $(\%)$ & $>2$ episodes $(\%)$ & \\
\hline $\begin{array}{l}\text { Age }(\boldsymbol{n}=52) \\
0-24 \text { months } \\
\text { More than } 24 \text { months }\end{array}$ & $\begin{array}{l}13(46.4) \\
15(53.6)\end{array}$ & $\begin{array}{l}02(08.3) \\
22(91.7)\end{array}$ & $\begin{array}{c}\chi^{2} \text { value }=9.32 \\
\mathrm{df}=1 \\
\mathbf{p}=\mathbf{0 . 0 0 3}\end{array}$ \\
\hline $\begin{array}{l}\operatorname{Sex}(n=52) \\
\text { Male } \\
\text { Female }\end{array}$ & $\begin{array}{l}21(75.0) \\
07(25.0)\end{array}$ & $\begin{array}{l}10(41.7) \\
14(58.3)\end{array}$ & $\begin{array}{c}\chi^{2} \text { value }=5.964 \\
\mathrm{df}=1 \\
\mathbf{p}=\mathbf{0 . 0 1 5}\end{array}$ \\
\hline $\begin{array}{l}\text { Circumcision }(\boldsymbol{n}=\mathbf{5 2}) \\
\text { Yes } \\
\text { No }\end{array}$ & $\begin{array}{l}02(07.1) \\
26(92.9) \\
\end{array}$ & $\begin{array}{l}04(16.7) \\
20(83.3) \\
\end{array}$ & $\begin{array}{c}\chi 2 \text { value }=1.15 \\
\mathrm{df}=1 \\
\mathrm{p}=0.284\end{array}$ \\
\hline $\begin{array}{l}\text { Constipation }(\boldsymbol{n}=52) \\
\text { Yes } \\
\text { No }\end{array}$ & $\begin{array}{l}11(39.3) \\
17(60.7)\end{array}$ & $\begin{array}{l}18(75.0) \\
06(25.0)\end{array}$ & $\begin{array}{c}\chi^{2} \text { value }=6.682 \\
\mathrm{df}=1 \\
\mathbf{p}=\mathbf{0 . 0 1 0}\end{array}$ \\
\hline $\begin{array}{l}\text { Bladder bowel dysfunction }(n=52) \\
\text { Yes } \\
\text { No }\end{array}$ & $\begin{array}{l}07(25.0) \\
21(75.0) \\
\end{array}$ & $\begin{array}{l}17(70.8) \\
07(29.2) \\
\end{array}$ & $\begin{array}{c}\chi^{2} \text { value }=10.92 \\
\mathrm{df}=1 \\
\mathbf{p}=\mathbf{0 . 0 0 1}\end{array}$ \\
\hline $\begin{array}{l}\text { Renal scarring on DMSA scan }(n=52) \\
\text { Scarring present } \\
\text { Scarring absent }\end{array}$ & $\begin{array}{l}08(28.6) \\
20(71.4)\end{array}$ & $\begin{array}{l}17(70.8) \\
07(29.2)\end{array}$ & $\begin{array}{c}\chi^{2} \text { value }=9.246 \\
\mathrm{df}=1 \\
\mathbf{p}=\mathbf{0 . 0 0 2}\end{array}$ \\
\hline
\end{tabular}




\section{Discussion}

In our study E. coli, Klebsiella species, Proteus mirabilis and $P$. aeruginosa were the common uropathogens in both primary and recurrent UTIs. These findings are similar to those of several large scale studies ${ }^{15-17}$. Enterococcus species and $P$. aeruginosa were significantly identified in recurrent childhood UT1s than in primary episodes. Other studies also reported Enterococcus species as an emerging organism in paediatric UTIs ${ }^{17,18}$. Frequency of $P$. aeruginosa in our setting was comparatively higher than in previous studies ${ }^{17-19}$. The percentages of ESBL positivity of primary and recurrent UTIs were $9.6 \%$ and $19 \%$ respectively and were far lower than results from a large study by Dogan $\mathrm{G}$, et al (primary $22 \%$, recurrent $37.4 \%$ ) $^{20}$. Moreover, prevalence of ESBL pathogens was estimated to be $37.7 \%$ in India, $30.5 \%$ in Iran and $41 \%$ in Turkey ${ }^{21}$.

The most striking finding of our study is the lower sensitivity of commonly used antibiotics to $E$. coli causing recurrent UTIs compared to primary episodes. Accordingly, the sensitivity of $E$. coli to cotrimoxazole was significantly lower $(p<0.05)$ while on long-term prophylactic antibiotics. In present study, E. coli showed highest sensitivity to imipenem, amikacin and ciprofloxacin. Our study is in keeping with the worldwide rates of highest resistance to ampicillin. Nitrofurantoin, cotrimoxazole and nalidixic acid were the other antibiotics which revealed $\leq 50 \%$ sensitivity to $\mathrm{E}$ coli. The sensitivity pattern of $E$. coli to commonly prescribed antibiotics was markedly different from other studies where nitrofurantoin had a higher sensitivity to this organism ${ }^{15,17,18,21,22}$. In one Sri Lankan study, nitrofurantoin, gentamycin and cefotaxime were identified as the most potent agents against coliforms, whereas ampicillin, cephalexin and cotrimoxazole were the least active agents ${ }^{23}$. In Bangladesh, Akhtar N, et al estimated $97.8 \%$ E coli resistance for cotrimoxazole ${ }^{24}$. An Iranian study by Mansouri $\mathrm{S}$, et $a l^{25}$ reported very high rates of resistance to cotrimoxazole $(93.6 \%)$, tetracycline $(84.5 \%)$ and ciprofloxacin $(40.4 \%)$. However, in the United States, considerably lower resistance was reported in the study by Khawcharoenporn $\mathrm{T}$, et al (ampicillin 55\%, co-amoxiclav 10\%, cotrimoxazole $24 \%$ and nitrofurantoin $14 \%)^{26}$. Several studies also revealed similar susceptibility rates for imipenem, amikacin, gentamycin and ciprofloxacin ${ }^{16,27}$. Klebsiella showed a high but variable sensitivity to the studied antibiotics as in previous studies ${ }^{15,20,23}$. We observed the lowest sensitivity of Klebsiella was to ampicillin which is similar to other studies ${ }^{15,20,23}$. As in present study, $P$. aeruginosa classically demonstrated high susceptibility to ceftazidime, amikacin and imipenem. Studies reported very low susceptibility of Enterococcus to aminoglycosides, ciprofloxacin and a rising trend for vancomycin resistance ${ }^{28,29}$. But we did not observe these findings in our cohort.

There is established consensus that when considering a first line empirical antibiotic for UTI, resistance rates should not be above $20 \%$ to the most likely pathogen ${ }^{15}$. Nevertheless, this threshold has been reached by many first line antibiotics used for childhood $E$. coli UTI. As in other studies, we noted that our studied microbial profile showed low sensitivity rates for nitrofurantoin, cotrimoxazole, co-amoxiclav and cefuroxime. The most likely reason for the high resistance rates for nitrofurantoin and cotrimoxazole is the common use of these antibiotics as prophylactic agents in patients with UTIs. Third generation cephalosporins, coamoxiclav and aminoglycosides are the most commonly used therapeutic agents for childhood $\mathrm{UTIs}^{30}$ and the high resistance rates observed for these antibiotics could be due to the fact that many UTIs are incompletely treated with an inadequate duration of antibiotics leading to the development of resistance. The free availability of these agents over the counter in local pharmacies, availability of oral preparations, vast usage of broad spectrum antibiotics without strict limitations for common paediatric infections and challenges related to infection control would be the most likely other explanations for the development of resistant strains with time.

The vast majority $(86 \%)$ of our study population had renal scarring. Previous reports demonstrated variable rates of kidney damage (21-89\%) based on DMSA findings ${ }^{31}$. A dramatic increase in the rate of renal scarring in children with UTI recurrences was demonstrated by Shaikh $\mathrm{N}$, et $a l^{31}$. A significant association was found between multiple recurrences and the presence of renal scarring according to the current study $(\mathrm{p}=0.002)$. The significantly higher rate of renal parenchymal scarring in our study may be explained by the sample bias as all had recurrent episodes with high rates of structural anomalies and BBD. The identification of a significant association between BBD and multiple recurrences $(p=0.001)$ in our study has also been shown by many other studies $^{31,32}$. The proportion of BBD in our sample $(46 \%)$ was clearly higher than what is reported in the general population, probably owing to the direct causal relationship between BBD and UTI. Symptom analysis of BBD in the present study was consistent with that of previous studies ${ }^{32}$. Similarly, constipation showed a significant association with repeated episodes of UTIs $(p=0.01)$, which was confirmed by other studies ${ }^{7,32}$. We could also demonstrate a significant female predominance in recurrent UTIs $(p=0.015)$ and this was in line with previous findings ${ }^{33}$. In addition, multiple recurrences are well described in infants aged less than 6 months $^{33}$. However, in our study population, 
occurrence of more than 2 recurrences was significantly higher in children older than 24 months. Thus, uroprophylaxis alone has a limited role in preventing recurrent UTI in children when there are provoking factors.

Our study has several strengths. This is the first study in Sri Lanka focusing on determining the clinical profile of recurrent UTIs in children. Moreover, we compared primary and recurrent episodes in relation to microbiological parameters. We were very strict in our inclusion criteria to recruit definite UTIs according to the NICE guidelines. The main limitations of this study are the relatively small sample size and the short study duration. Furthermore, as details were extracted from medical records, we had to exclude a large number of cases where information was not clearly documented. The study cohort, being managed in a tertiary care centre, might not represent the general paediatric group. Since we primarily focused on determining the sensitivity patterns we could not achieve a comprehensive account on antibiotic resistance. Nevertheless, identifying the uropathogens and their antimicrobial susceptibilities and risk factors is helpful to guide management including deciding the empirical therapy and preventing recurrences. Further, as the sensitivity patterns of microorganisms vary over time and among different geographical locations, management should be based on local evidence.

The haphazard use of antibiotic prophylaxis as well as inadequate treatment of proven UTIs are the likely causes of the development of resistance and should be discouraged. We advocate a meticulous case-based approach to decide on the empirical and treatment antibiotics to mitigate the possible complications. Authors highlight the importance of regular surveillance to determine the local prevalence of organisms and antibiotic susceptibilities and screening for risk factors in order to guide the proper management of these children.

\section{Conclusions}

Both primary and recurrent UTIs in children are mainly caused by E. coli. The sensitivity pattern of E coli to commonly prescribed antibiotics was relatively low. The antibiotic sensitivity rates of $E$. coli were comparatively lower in recurrent UTIs and a significantly lower susceptibility was noted with cotrimoxazole. Multiple UTI recurrences were significantly associated with age above 24 months, female gender, constipation, BBD and renal scarring.

\section{Acknowledgements}

Authors are thankful to Dr. Roshan Rambukwella and Prof. Sampath Tennakoon, for the support extended in statistical analysis.

\section{References}

1. De Silva ACS, Oliveira EA. Update on the approach of urinary tract infection in childhood. Jornal de Pediatria 2015; 91 (6 Suppl 1): S2-S10. https://doi.org/10.1016/j.jpedp.2015.09.00 8

PMid: 26361319

2. Wu T, Huang F, Fu L, Chou C, Chien Y, Huang $\mathrm{C}$, et al. Treatment of recurrent complicated urinary tract infections in children with vesicoureteral reflux. Journal of Microbiology, Immunology and Infection 2016; 49: 717-22.

https://doi.org/10.1016/j.jmii.2014.08.024 PMid: 25442872

3. Craig JC, Simpson JM, Williams GJ, Lowe A, Reynolds GJ, et al. Antibiotic prophylaxis and recurrent urinary tract infection in children. New England Journal of Medicine 2009; 361: 1748-59. https://doi.org/10.1056/NEJMoa0902295 PMid: 19864673

4. Tewary K, Narchi H. Recurrent urinary tract infections in children: Preventive interventions other than prophylactic antibiotics. World Journal of Methodology 2015; 5(2): 13-9.

https://doi.org/10.5662/wjm.v5.i2.13

PMid: 26140267 PMCid: PMC4482817

5. Kutasy B, Coyle D, Fossum M. Urinary tract infection in children: Management in the era of antibiotic resistance-A paediatric urologist's view. European Urology Focus 2017; 3; 207-11.

https://doi.org/10.1016/j.euf.2017.09.013

PMid: 28965960

6. Paintsil E. Update on recent guidelines for the management of urinary tract infections in children: the shifting paradigm. Current Opinion in Pediatrics 2013; 25(1): 88-94. https://doi.org/10.1097/MOP.0b013e3283 $5 \mathrm{c} 14 \mathrm{cc}$

PMid: 23241875 PMCid: PMC4880363

7. Karen R, Shaikh N, Pohl H, GravensMueller L, Ivanova A et al. Risk factors for recurrent urinary tract infection and renal scarring. Pediatrics 2015; 136(1). 
https://doi.org/10.1542/peds.2015-0409 PMid: 26055855 PMCid: PMC4485012

8. Montini G, Rigon L, Zucchetta P, Fregonese F, Toffolo A et al. Prophylaxis after first urinary tract infection in children? A multicentre, randomized, controlled, non-inferiority trial. Pediatrics 2008; 122(5): 1064-71.

https://doi.org/10.1542/peds.2007-3770

PMid: 18977988

9. Roussey-Kesler G, Gadjos V, Idres N, Horen B, Ichay L et al. Antibiotic prophylaxis for the prevention of recurrent UTI in children with low grade VUR: results from a prospective randomized study. Journal of Urology 2007; 179(2): 674-9.

https://doi.org/10.1016/j.juro.2007.09.090 PMid: 18082208

10. Farhat W, Bägli DJ, Capolicchio G, O'Reilly S, Merguerian PA et al. The dysfunctional voiding scoring system: quantitative standardization of dysfunctional voiding symptoms in children. Journal of Urology 2000; 164: 1011-5.

https://doi.org/10.1016/S00225347(05)67 239-4

11. Zeevenhooven J, Koppen IJN, Benninga MC. The new Rome IV criteria for functional gastrointestinal disorders in infants and toddlers. Pediatric Gastroenterology, Hepatology and Nutrition 2017; 20(1): 1-13.

https://doi.org/10.5223/pghn.2017.20.1.1

PMid: 28401050 PMCid: PMC5385301

12. National Institute for Health and Care Excellence - UTI in children, Evidence update October 2017.

13. Goldraich NP, Ramos OL, Goldraich IH. Urography versus DMSA scan in children with vesico-ureteric reflux. Pediatric Nephrology 1989; 3(1): 1-5. https://doi.org/10.1007/BF00859614 PMid: 2562013

14. Conway PH, Cnaan A, Zaoutis T, Henry BV, Grundmeier RW, Keren R. Recurrent urinary tract infections in children: risk factors and association with prophylactic antimicrobials. Journal of the American Medical Association 2007; 298(2): 17986. https://doi.org/10.1001/jama.298.2.179

PMid: 17622599

15. Gunduz S, Altun HU. Antibiotic resistance patterns of urinary tract pathogens in Turkish children. Global Health Research and Policy 2018; 3:10.

PMCID: PMC5856228

DOI: $10.1186 / \mathrm{s} 41256-018-0063-1$ https://doi.org/10.1186/s41256-018-00631

PMid: 29568806 PMCid: PMC5856228

16. Mirsoleymani SR, Salimi M, Brojeni MS, Ranjbar M, Mehtarpoor M. Bacterial pathogens and antimicrobial resistance patterns in paediatric urinary tract infections: a four-year surveillance study (2009-2012). International Journal of Pediatrics 2014; 5:126142.

https://doi.org/10.1155/2014/126142

PMid: 24959183 PMCid: PMC4052188

17. Sorlózano-Puerto A, Gómez-Luque JM, Luna-del-Castillo JD, Navarro-Marí JM, GutiérrezFernández J: Aetiological and resistance profile of bacteria involved in urinary tract infections in young children. BioMed Research International 2017; 2017:4909452.

https://doi.org/10.1155/2017/4909452

PMid: 28497052 PMCid: PMC5405357

18. Singh SD, Madhup SK. Clinical profile and antibiotics sensitivity in childhood urinary tract infection at Dhulikhel hospital. Kathmandu University Medical Journal 2013; 11(44): 319-24.

https://doi.org/10.3126/kumj.v11i4.12541 PMid: 24899328

19. Hameed T, Nafeesah AA, Chishti S, Shaalan MA, Fakeeh KA. Communityacquired UTI in children: resistance patterns of uropathogens in a tertiary care centre in Saudi Arabia. International Journal of Pediatrics and Adolescent Medicine 2019; 6(2): 51-4.

https://doi.org/10.1016/j.ijpam.2019.02.01 0

PMid: 31388546 PMCid: PMC6676371

20. Dogan G, Ipek H. Comparison of primary and recurrent urinary tract infections in children. Cureus 2020; 12(2): e7019. https://doi.org/10.7759/cureus.7019

21. Awean GZA, Salameh K, Elmohamed H, Alshmayt H, Omer MRB. Prevalence of ESBL urinary tract infection in children. 
Journal of Advanced Pediatrics and Child Health 2019; 2: 4-7.

https://doi.org/10.29328/journal.japch.100 1004

22. Edlin RS, Shapiro DJ, Hersh AL, Copp HL. Antibiotic resistance patterns in outpatient pediatric UTI. Journal of Urology 2013; 190(1): 222-7.

https://doi.org/10.1016/j.juro.2013.01.069

PMid: 23369720 PMCid: PMC4165642

23. Shrestha LB, Baral R, Poudel P, Khanal B. Clinical, aetiological and antimicrobial susceptibility profile of paediatric UTI in a tertiary care hospital of Nepal. BMC Pediatrics 2019; 19(1): 36. https://doi.org/10.1186/s12887-019-14101

PMid: 30696410 PMCid: PMC6350346

24. Senanayake NP, Chandrasiri NS. Analysis of causative agents of UTI in children and their antibiotic sensitivity pattern: a hospital based study. Sri Lanka Journal of Child Health 2015; 44(4): 197-201. https://doi.org/10.4038/sljch.v44i4.8042

25. Akhtar N, Rahman R, Sultana S. Antimicrobial sensitivity pattern of Escherichia coli causing UTI in Bangladeshi patients. American Journal of Microbiological Research 2016; 4(4): 1225.

26. Mansouri S, Abbasi S. Prevalence of multiple drug resistant clinical isolates of extended-spectrum beta-lactamase producing Enterobacteriaceae in Southern Iran. Iranian Journal of Medical Sciences 2010; 35(2): 101-108.

27. Khawcharoenporn T, Vasoo S, Singh K. UTI due to multi-drug resistant Enterobacteriaceae: prevalence and risk factors in a Chicago emergency department. Emergency Medicine International 2013; 2013: 258517. https://doi.org/10.1155/2013/258517 PMid: 24307946 PMCid: PMC3844142

28. Shakya P, Shrestha D, Maharjan E, Sharma VK, Paudyal R. ESBL production among
E. coli and Klebsiella spp. causing UTI: a hospital based study. The Open Microbiology Journal 2017; 11: 23-30. https://doi.org/10.2174/187428580171101 0023

PMid: 28553414 PMCid: PMC5427687

29. Taneja N, Chatterjee SS, Singh M, Singh S, Sharma M. Paediatric UTI in a tertiary care centre from north India. Indian Journal of Medical Research 2010; 131: 101-5.

30. Govindarajan S, Shenoy PJ. Drug prescribing patterns in paediatric urinary tract infections: a retrospective drug utilization analysis in an urban tertiary care hospital. Journal of Pharmacy and BioAllied Sciences 2020; 12(4): 423-27 https://doi.org/10.4103/JPBS.JPBS_235_1 9

PMid: 33679088 PMCid: PMC7909065

31. Shaikh N, Hoberman A, Keren R, Gotman $\mathrm{N}$, Docimo $\mathrm{SG}$, Mathews $\mathrm{R}$, et al. Recurrent urinary tract infections in children with bladder and bowel dysfunction. Pediatrics 2016; 137(1): e20152982.

https://doi.org/10.1542/peds.2015-2982 PMid: 26647376 PMCid: PMC4702025

32. Panaretto KS, Craig JC, Knight JF, Howman-Giles R, Sureshkumar P, Roy LP. Risk factors for recurrent urinary tract infection in pre-school children. Journal of Paediatrics and Child Health 1999; 35: 454-9. https://doi.org/10.1046/j.14401754.1999.3 55417.x

PMid: 10571758

33. Shim YH, Lee JW, Lee SJ. The risk factors of recurrent urinary tract infection in infants with normal urinary systems. Pediatric Nephrology 2009; 24(2): 309312. https://doi.org/10.1007/s00467-008-10010 PMid: 18830717 